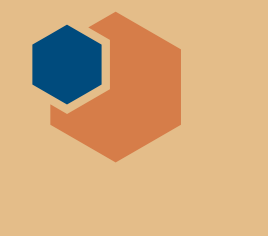

\section{Scientists initiate grassroots efforts to show importance of STEM to US government}

$\mathrm{P}$ olicymakers in the United States over the years have held many discussions about what "type" of science the US government should be supportingfrom the most basic research, to development and commercialization of more advanced research, to moonshot technology ideas. In addition, debates have raged in Congress on using funding and incentives to pick "winners and losers" in certain technology areas (i.e., funding clean energy technologies versus supporting fossil fuels) or finding ways to provide general support and let the market decide technology outcomes. Lastly, with the need to cut the national deficit, all budgets, including those that support science, have come under scrutiny and faced cuts or flat funding in many areas.

Despite these issues, science has received relatively broad bipartisan support within the US government. The landmark bill that authorized and guided science policy over the last decade, the America Creating Opportunities to Meaningfully Promote Excellence in Technology, Education, and Science (COMPETES) Act was first passed in 2007 with a Democratic majority in both houses of Congress and under Republican President George W. Bush. Reauthorized in 2010, COMPETES never quite reached its goal to double the basic sciences research budget, but bipartisan support for science continued with the January 2017 passage of the American Innovation and Competitiveness Act (AICA). A successor to COMPETES, the AICA was passed by a Republican-controlled Congress and signed by Democratic President Barak Obama in the final days of his presidency (reported in the March 2017 issue of MRS Bulletin, doi:10.1557/mrs.2017.43).

From economic growth, to improved health and quality of life, to enhanced national security - politicians generally

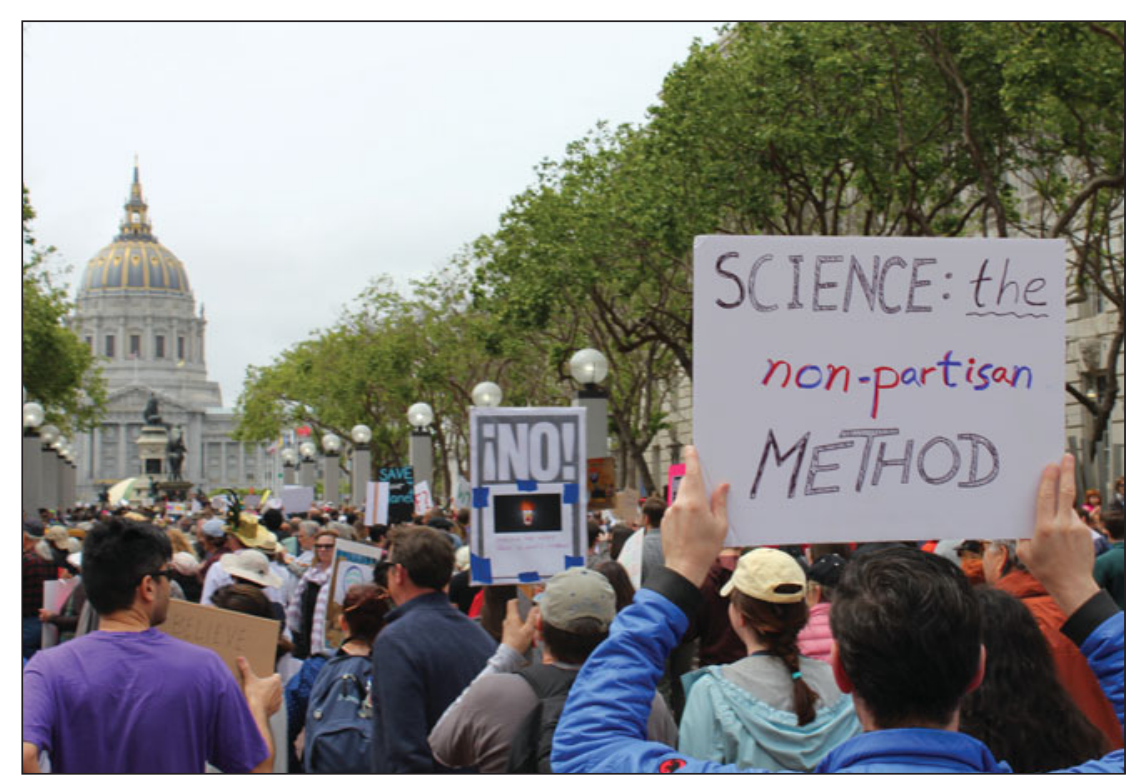

Participants in the March for Science in San Francisco on April 22, 2017, call for nonpartisan support for science in policy decisions. Photo credit: Alison Hatt. recognize the overarching results of government investment in science. A clear example of this can be found in the AICA, which characterizes contributions of federally funded basic research conducted by the National Science Foundation (NSF) as "scientifically and societally relevant," and specifically calls out economic growth, human health benefits, and contributions to national security.

However, while some of the benefits of federally funded science are largely acknowledged across party lines, funding science has become increasingly politicized over the last several years. A looming example of this is the partyline division of politicians on the issue of climate change. Democrats largely acknowledge the scientific consensus that human-made pollution is the predominant factor driving climate change. Conversely, Republicans range from questioning the science behind climate change to outright denial that humans have any impact on it. The politicization of this issue has led to vastly different ideas within Congress of whether federal money should be spent on research and technologies that could reduce the release of pollutants tied to climate change.

Add to that the Trump administration's denial of climate change, abrupt changes in staffing as well as available content and data within key sciencebased agencies, and the administration's FY 2018 budget request that makes significant slashes in science funding across the government agencies, and suddenly science has seemingly become very political. Of specific concern to the materials research community are the administration's proposed budget cuts for basic and applied research within the Department of Defense (nearly 6\%); the Division of Materials Research within the NSF (9\%); the Mathematical and Physical Sciences Directorate within the NSF (nearly 10\%); and the Department of Energy's Office of Science (17\%, which includes a $16.9 \%$ cut for Basic Energy Sciences and proposed elimination of the Advanced Research Projects Agency-Energy program). In addition to these key agencies and programs that support materials research, the National 
Institutes of Health is facing a proposed cut of $\$ 7.2$ billion that would impact biomaterials research.

The combination of these events has served as a catalyst for action within the science, technology, engineering, and mathematics (STEM) community. Grassroots efforts have sprung up around the country and the already established routes of science advocacy have attracted increasing numbers of participants. One notable grassroots effort was the March for Science and its continuing movement. On Earth Day, April 22, 2017, scientists and science supporters in over 600 cities-internationally — marched, kicking off a movement to "champion science for the common good," which according to the event's website, includes strengthening the role of science in policymaking, improving science outreach and communication, advancing science education and scientific literacy, and fostering a diverse and inclusive scientific community. Endorsed by over 100 science organizations, including a statement of support from the Materials Research Society (MRS), the March for Science is estimated to have drawn over 1 million marchers worldwide, including materials researchers (reported in the July 2017 issue of MRS Bulletin, doi:10.1557/ mrs.2017.152).

While an unprecedented number of scientists and science supporters marched, the March for Science also drew some criticism from the science community. The largest issues raised stemmed from concern that a march is inherently political and could further politicize science in the public eye. Indeed, many scientists and scientific societies exercise caution when weighing in on science policy issues because of the belief that science should not be political or partisan. And while the march was cast as a political act more in some cities than in others, the mission of the March for Science directly states, "We unite as a diverse, nonpartisan group to call for science that upholds the common good and for political leaders and policymakers to enact evidence based policies in the public interest."

Another significant grassroots effort driven by the STEM community is 314 Action. With a board of advisors filled

Grassroots organizations support STEM in US policy

March for Science www.marchforscience.com

Mission: Call for political leaders and policymakers to enact evidence-based policies in the public interest

314 Action www.314action.org

Mission: Elect more leaders from STEM backgrounds to political office

ScienceCounts www.sciencecounts.org

Mission: Enhance public awareness of, and support for, federally funded scientific research

with scientists, entrepreneurs, academics, medical doctors, and a political strategist, 314 Action has quickly grown to include volunteer leadership in 35 states and the District of Columbia as well as over 75 active student chapters on college campuses across the country. The nonprofit borrows part of its name from Pi because of the ubiquity of Pi within science and ubiquity of science within the world. 314 Action's mission statement says the organization is "committed to electing more leaders who will use their training as STEM professionals to influence policy-making." In the US Congress, only a handful of STEM professionals have served at any time. Kevin Whittlesey, chair of the Government Affairs Committee of MRS, says that "there are many policy issues which profoundly impact the STEM fields and community. It is critically important that elected officials include STEM professionals, who will bring technical expertise and firsthand knowledge of the impacts policy decisions will have on the STEM fields."

One of the ways that 314 Action hopes to bolster the numbers of STEM professionals in office is by providing support and services like in-person and video training for those interested in running for office. "STEM professionals do not typically seek elected offices so there is a significant opportunity to educate STEM professionals about these kinds of positions, the ways in which they serve the STEM community, and how to pursue elected office," Whittlesey says. In addition to electing more STEM leaders, 314 Action advocates for a pro-science agenda that will include solutions to climate change and help combat what they call "attacks on basic scientific understanding." 314 Action has also established a program called "Under the Scope" that targets members of Congress who the organization considers anti-science and magnifies the members' positions on science policy.

ScienceCounts is another recently established organization driven by STEM professionals to promote support for federal funding of scientific research. The nonprofit is supported by a range of partners including several scientific societies, a number of philanthropic foundations, and a few technology-based companies. According to Alan Hurd, former president of MRS and now chair of the ScienceCounts Board of Directors, ScienceCounts is aimed at the public and founded on "political campaign techniques" like using media campaigning to change public perception of, and support for, federally funded science. To date, ScienceCounts has conducted a nationwide study to better understand public attitudes toward science and identify ways to engage with the public on science. The second step in ScienceCounts' self-described "national public engagement campaign" is a test campaign that is currently under way and involves "three large media markets in the US," Hurd says. The final step of the initiative will kick off after the test campaign is complete, and will be a full campaign to bolster public support for federal science research.

To learn more about the efforts listed here, reference the links above. In addition, stay tuned for the September issue of MRS Bulletin that will include the second part of this article and outline many of the established routes for science advocacy that have been attracting increased support from STEM professionals.

Jennifer A. Nekuda Malik 


\section{MIIS' FALL MEETING \& EXHBI}

November 26-December 1, 2017 | Boston, Massachusetts

\section{PREREGISTRATION OPENS PREREGISTRATION MID-SEPTEMEER}

BROADER IMPACT

BI01 Community College and University Partnerships as Catalysts for Promoting Materials Science Education

BI02 Materials Innovation for Sustainable Agriculture and Energy

\section{BIOMATERIALS AND SOFT IMATERIALS}

BM01 Multiscale Mechanobiology and BiomechanicsTheory, Experiments, Computations

BM02 Multiphase Fluids for Materials ScienceDroplets, Bubbles and Emulsions

BM03 Biological and Bioinspired Materials for Photonics and ElectronicsFrom Living Organisms to Devices

BM04 Biomaterials for Regenerative Engineering

BM05 Polymer Gels in Materials Science-

3D/4D Printing, Fundamentals and Applications

BM06 2D Nanomaterials in Health Care

BM07 Emerging Materials and Devices for Engineering Biological Function and Dynamics

BM08 Materials Design for Neural Interfaces

BM09 Stretchable Bioelectronics-

From Sensor Skins to Implants and Soft Robots

BM10 Bioinspired Interfacial Materials with Superwettability

BM11 Modeling, Characterization, Fabrication and Applications of Advanced Biopolymers-Where Form Meets Function

BM12 Biomolecular Self-Assembly for Materials Design

\section{ELECTRONICS, MAGNETICS AND PHOTONICS}

EM01 Organic Semiconductors-Surface, Interface, Bulk Doping and Charge Transport

EM02 Multiferroics and Magnetoelectrics

EM03 Novel Materials and Architectures for PlasmonicsFrom the Ultraviolet to the Terahertz

EM04 Wide- and Ultra-Wide-Bandgap Materials and Devices

EM05 Oxide Interfaces-Lattice and Electronic Defect Interactions

EM06 Diamond Electronics, Sensors and BiotechnologyFundamentals to Applications

EM07 Materials, Devices and Architectures for Neuromorphic Engineering and Brain-Inspired Computing

EM08 Emerging Materials for Quantum Information

EM09 Electronic and Ionic Dynamics at Solid-Liquid Interfaces

EM10 Solution-Processed Inorganics for Electronic and Photonic Device Applications

\section{ENERGY AND SUSTAINABILITY}

ES01 Perovskite Materials and Devices-Progress and Challenges

ES02 On the Way to Sustainable Solar FuelsNew Concepts, Materials and System Integration

ES03 Earth Abundant Metal Oxides, Sulphides and Selenides for Energy Systems and Devices

ES04 Interfaces in Electrochemical Energy Storage

ES05 Materials and Design for Resilient Energy Storage

ES06 Alkali Solid Electrolytes and Solid-State Batteries

ES07 Chromogenic Materials and Devices

ES08 Advanced Nuclear Materials-Design, Development and Deployment

ES09 Thermal Energy-Transfer, Conversion and Storage

ES10 Materials Efficiency to Enable a Circular Materials Economy

ES11 Silicon for Photovoltaics

\section{NANOMATERIALS}

NM01 Carbon Quantum Dots-Emerging Science and Technology NM02 Anisotropic Carbon Nanomaterials-Frontiers in Basic and Applied Research

NM03 Progress in Developing and Applications of Functional One-Dimensional Nanostructures

NM04 Atomically Thin, Layered and 2D Non-Carbon Materials and Systems

NM05 Nanomaterials, Nanoparticles and Nanostructures Produced by PlasmasSynthesis, Characterization and Applications

NM06 Semiconductor Nanocrystals, Plasmonic Nanoparticles and Metal-Hybrid Structures

NM07 Nanostructure-Based Optical Bioprobes-Advances, Trends and Challenges in Optical and Multimodular Bioimaging and Sensing

NM08 Defect-Induced Phenomena and New States of Matter at the Nanoscale

\section{PROCESSING AND MANUFACTURING}

PM01 Explore New Frontiers in Materials Design Using PlasmasSynthesis, Processing and Characterization

PM02 Advances and Upcoming Research Strategies in Reactive Materials

PM03 Interfaces and Interface Engineering in Inorganic Materials

PM04 Micro-Assembly Technologies-Fundamentals to Applications

\section{THEORY, CHARACTERIZATION AND MODELING}

TC01 Multifunctional and Multifrequency Scanning Probe Microscopy

TC02 In Situ Studies of Materials Transformations

TC03 Emerging Prospect and Capabilities in Ion Beam Technology and Applications

TC04 Advanced Atomistic Algorithms in Materials Science

TC05 Uncertainty Quantification in Multiscale Materials Simulation

TC06 Mechanical Behavior at the Micro and NanoscaleBridging Between Computer Simulations and Experiments

TC07 Design, Control and Advanced Characterization of Functional Defects in Materials

\section{Meeting Chairs}

Ilke Arslan Pacific Northwest National Laboratory Jason A. Burdick University of Pennsylvania Tao Deng Shanghai Jiao Tong University James B. Hannon IBM T.J. Watson Research Center Sanjay Mathur University of Cologne

www. mrs.org/fall2017

2017 iMatSci Innovator Showcase CALL FOR EARLY-STAGE STARTUPS Submission Deadline: September 1, 2017 www.mrs.org/imatsci

\section{R S MATERIALS RESEARCH SOCIETY}

506 Keystone Drive • Warrendale, PA 15086-7573 Tel 724.779.3003 • Fax 724.779 .8313 info@mrs.org・www.mrs.org 